\title{
A Study on the Occupational Carbon Footprint and Environmental Sustainability
}

\author{
Lalithambigai.Ma ${ }^{\mathrm{a}}$, Kavya.G ${ }^{\mathrm{b}}$, Akshaya. P $^{\mathrm{c}}$, Aswathi Baburaj \\ ${ }^{a}$ Department of Economics, PSGRKCW, Coimbatore, TN, India \\ ${ }^{\mathrm{b}}$ Department of Economics, PSGRKCW, Coimbatore, TN, India \\ ${ }^{c}$ Department of Economics, PSGRKCW, Coimbatore, TN, India \\ dDepartment of Economics, PSGRKCW, Coimbatore, TN, India \\ govindarajankavya7@gmail.coma, lalithambigai@psgrkcw.ac.inb, akshayapandiarajan@gmail.comc, \\ aschukichu19@gmail.comd
}

Article History: Received: 10 November 2020; Revised 12 January 2021 Accepted: 27 January 2021; Published online: 5 April 2021

\begin{abstract}
Global Warming is a well renowned common threat and carbon dioxide is its core which places the entire ecosystem under grave peril. Carbon footprint is an effective tool to measure the menacing acts which emit innumerable amounts of carbon. This study majorly focuses on the influence of income and commute on the Carbon Footprint and Environmental Sustainability. It is designed in such a way to explicitly pinpoint the causes of carbon emissions under various heads like commute, travel, diet, energy and family spend. Primary data from five major subdivisions of population like Entrepreneurs, Home makers, Labors, Professionals and students were considered for the study purpose. A questionnaire that combines general questions and access to a virtual carbon footprint calculator (Shado Calculator) was used to find out the carbon emission of the individual respondent. The findings state that the average carbon footprint increase with an increase in the income level and it is also shaped by commute emissions which contribute the most to the overall carbon footprint. The carbon footprint is generally determined by the occupational and financial soundness. Required initiatives in the form of individual efforts and changes in policy implications must be undertaken at all the levels of the society to control and downsize the impact of the carbon footprint on the environment.
\end{abstract}

Keywords: Carbon footprint, local travel, Travel, food-based emissions, Energy induced emissions, Family spending and annual income.

\section{Introduction}

The world has become more susceptible to climate change with the advent of increasing carbon emission levels. Carbon emission mainly comprises of carbon dioxide, methane, nitrous oxide, and several fluorinated pollutants that form the Green House Gases. These vicious particles get trapped in the atmosphere and pollute the environment. Our travel choice, diet, lifestyle choices, and energy consumption determine the size of our carbon footprint, in simple terms, a carbon footprint calculator quantifies our impact on the environment. (Seriño 2016) Results showed that the highest carbon-emitting goods consumed by households are related to expenditure on fuel, light and transportation while nondurable and recreation goods were the least carbon-intensive. By using non-parametric estimation, results showed a strong positive relationship between household carbon footprint and income but the effect varies across the distribution. This implies that further increases in carbon footprint are to be expected as households get richer. Climate change occurs due to predominant amounts of carbon in the atmosphere. Carbon (CO2) is the most influential gases among all other gases because they are mainly heattrapping gases. Because of which it poses a great threat by placing the humankind at the greatest risk of irreversible changes which prolonged might even accumulate in an unabated manner in the atmosphere. Such carbon is aptly released from our daily acts such as travel, consumption, electricity usage, procuring, Expenditure and much more. This is measured in the forms of carbon footprint. An online carbon footprint calculator (Shado Calculator) works based on the inputs fed to the questions which are centred on emission causing agents. (Irfany and Klasen 2016)The results show that as per capita expenditure increases, within-group emission inequality tends to decline until the middle-income group but then further increase in expenditure worsens emission inequality. The decomposition of inequality based on emission sources suggests energy-transportation predominantly contributes to the overall emission inequality; that According to the answers given, the calculator generates a report of the individual carbon footprint under several heads. Carbon footprint calculated using the virtual calculator was undertaken for the analysis. Hence measuring it and the realization of its negative significance towards the environment has been laid as the fundamental problem in this study.

The main objective of the thesis is to analyze the carbon footprint of each respondent and to discover the highest contributing factor in terms of carbon emission associated with the individual respondent and to suggest 
individual alternatives to overcome it. To understand the relationship between the annual incomes, commute of the respondents and total carbon emission.

Primary data from 125 respondents was compiled in this paper because first-hand information is considered more secure and reliable. Five major subdivisions of population like Entrepreneurs, Home makers, Labors, Professionals and students were considered for the study purpose. Prior approval was obtained from the owner of the carbon footprint calculator from the website www.onlyplanet.in. $\mathrm{CO} 2 \mathrm{e}$ refers to the carbon footprint equivalent per year.

\subsection{Respondent and their Occupation}

The data from the table 1 depicts the uniform distribution of the respondent's concerning their professions, entrepreneurs, homemakers, labours, professionals and students. Entrepreneurs in our study refer to people who own business as the main occupation. Homemakers refer to the unemployed dependents, Labors include respondents from eateries and construction sectors, Professionals include doctors, advocates, professional dancers and accountants, Students means school and college pursuing students.

Table1: classification of the respondent based on their occupations.

\begin{tabular}{|l|c|c|}
\hline Category & No. of Respondents & Percentage (\%) \\
\hline Entrepreneurs & 25 & 20 \\
\hline Home Makers & 25 & 20 \\
\hline Labours & 25 & 20 \\
\hline Professionals & 25 & 20 \\
\hline Students & 25 & $\mathbf{1 0 0}$ \\
\hline Total & $\mathbf{1 2 5}$ & 20 \\
\hline
\end{tabular}

Equally, 25 respondents fall under each category and individually contribute $20 \%$ to the overall percentage.

\subsection{Total average carbon emissions for all categories}

The data from the succeeding table 2 distinctively compares the variations in the selected variables like commute emissions, food and water consumption induced emissions, travel emissions, emissions from energy consumptions and emissions from family spending amidst different occupations per year is being calculated.

Table 2: Classification of the respondent based on their occupation and their corresponding carbon footprint

\begin{tabular}{|c|c|c|c|c|c|c|c|}
\hline Category & $\begin{array}{c}\text { Carbon } \\
\text { emissions } \\
\& \\
\text { percentage }\end{array}$ & $\begin{array}{c}\text { Commute } \\
\mathrm{Kg} \text { in } \\
\mathrm{Co} 2 \mathrm{e}\end{array}$ & $\begin{array}{l}\text { Food/ } \\
\text { Water } \\
\text { Kg in } \\
\text { Co2e }\end{array}$ & $\begin{array}{l}\text { Travel } \\
\mathrm{Kg} \text { in } \\
\mathrm{Co2e}\end{array}$ & $\begin{array}{c}\text { Energy } \\
\mathrm{Kg} \text { in } \\
\text { Co2e }\end{array}$ & $\begin{array}{l}\text { Family } \\
\text { Spend } \\
\text { Kg in } \\
\text { Co2e }\end{array}$ & $\begin{array}{c}\text { Total } \\
\text { Kg in } \\
\text { CO2e/per } \\
\text { year }\end{array}$ \\
\hline \multirow{2}{*}{ Entrepreneur } & $\begin{array}{c}\text { Carbon } \\
\text { emissions }\end{array}$ & 12241.8 & 354.08 & 171 & 617.28 & 751.04 & 14135.2 \\
\hline & percentage & $86.6 \%$ & $2.5 \%$ & $1.2 \%$ & $4.3 \%$ & $5.3 \%$ & 100 \\
\hline \multirow{2}{*}{ Home Maker } & $\begin{array}{c}\text { Carbon } \\
\text { emissions }\end{array}$ & 407.72 & 222 & 14.36 & 401.24 & 137 & 1182.32 \\
\hline & percentage & $34.48 \%$ & $18.7 \%$ & $1.2 \%$ & $33.9 \%$ & $11.5 \%$ & 100 \\
\hline \multirow{2}{*}{ Labourers } & $\begin{array}{l}\text { Carbon } \\
\text { emissions }\end{array}$ & 1307.92 & 369.72 & 40.16 & 462.96 & 367.92 & 2548.68 \\
\hline & percentage & $51.3 \%$ & $14.5 \%$ & $1.5 \%$ & $18.1 \%$ & $14.4 \%$ & 100 \\
\hline
\end{tabular}




\begin{tabular}{|c|c|c|c|c|c|c|c|}
\hline \multirow{2}{*}{ Professionals } & $\begin{array}{c}\text { Carbon } \\
\text { emissions }\end{array}$ & 2552.32 & 368.08 & 1583.32 & 1034.32 & 342.84 & $\mathbf{5 8 8 0 . 8 8}$ \\
\cline { 2 - 8 } & percentage & $\mathbf{4 3 . 4 \%}$ & $\mathbf{6 . 2 \%}$ & $\mathbf{2 6 . 9 \%}$ & $\mathbf{1 7 . 5 \%}$ & $\mathbf{5 . 8 \%}$ & $\mathbf{1 0 0}$ \\
\hline \multirow{3}{*}{ Students } & $\begin{array}{c}\text { Carbon } \\
\text { emissions }\end{array}$ & 1610.84 & 329.54 & 100.12 & 459.96 & 306.32 & $\mathbf{2 8 0 6 . 7 8}$ \\
\cline { 2 - 8 } & percentage & $\mathbf{5 7 . 3 \%}$ & $\mathbf{1 1 . 7 \%}$ & $\mathbf{3 . 5 6 \%}$ & $\mathbf{1 6 . 3 \%}$ & $\mathbf{1 0 . 9 \%}$ & $\mathbf{1 0 0}$ \\
\hline \multirow{2}{*}{ Total } & $\begin{array}{c}\text { Carbon } \\
\text { emissions }\end{array}$ & 18120.6 & 1643.42 & 1908.96 & 2975.76 & 1905.1 & $\mathbf{2 6 5 5 3 . 8 6}$ \\
\cline { 2 - 8 } & $\begin{array}{c}\text { percentage } \\
\end{array}$ & $\mathbf{6 8 . 2 \%}$ & $\mathbf{6 . 1 \%}$ & $\mathbf{7 . 1 \%}$ & $\mathbf{1 1 . 2 \%}$ & $\mathbf{7 . 1 \%}$ & $\mathbf{1 0 0}$ \\
\hline
\end{tabular}

$86 \%$ of the entrepreneur's emissions come from commute followed by $2 \%$ from food and water-induced emissions, $1 \%$ from travel emissions, $4 \%$ from energy-based emissions and $5 \%$ of emissions from family spending while the total average emissions of entrepreneurs have come up to 14135 kilograms of Co2e per year. $34 \%$ of the homemakers emissions come from commute followed by $18 \%$ from food and water-induced emissions, $1 \%$ from travel emissions, $33 \%$ from energy-based emissions and $11 \%$ of emissions from family spending while the total average emissions of home makers have come up to 1182 kilograms of Co2e per year. $51 \%$ of the labours emissions come from commute followed by $14 \%$ from food and water-induced emissions, $1 \%$ from travel emissions, $18 \%$ from energy-based emissions and $14 \%$ of emissions from family spending while the total average emissions of labours have come up to 2548 kilograms of Co2e. $43 \%$ of the professionals emissions come from commute followed by $6 \%$ from food and water-induced emissions, $27 \%$ from travel emissions, $17 \%$ from energy-based emissions and 5\% of emissions from family spending while the total average emissions of professionals have come up to 5880kilograms of Co2e. 57\% of the students emissions come from commute followed by $11 \%$ from food and water-induced emissions, $3 \%$ from travel emissions, $16 \%$ from energy-based emissions and $7 \%$ of emissions from family spending while the total average emissions of students have come up to 2806 kilograms of Co2e.

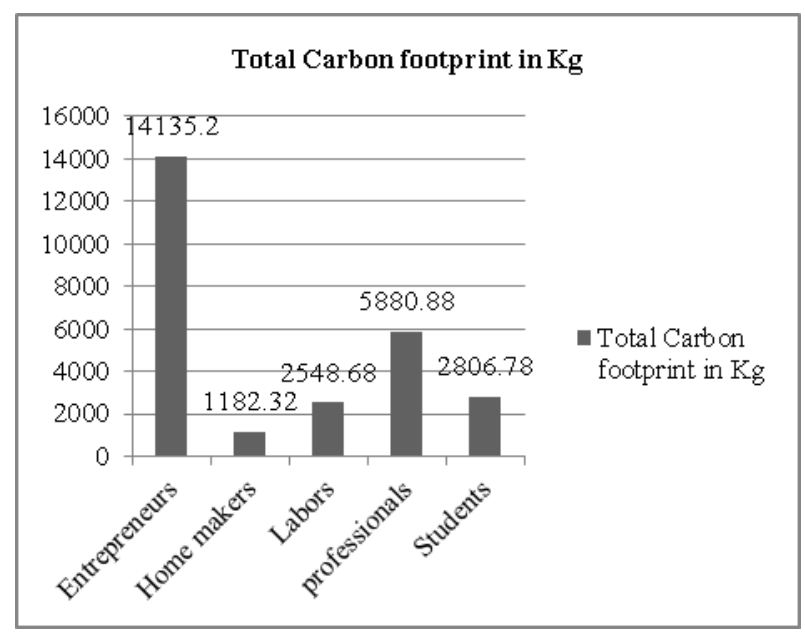

\subsection{Relationship between commute and total carbon footprint}

The correlation analysis is carried out to find out the relationship between commute and total carbon footprint. The analysis shows 95 per cent correlation between these two variables. In other words, it is positively correlated and assures the relationship through the significance level which is 0.01 . This proves that when there is an increase in commute variable there is a corresponding increase in total carbon footprint. It can be concluded that the total carbon footprint of the individual respondent has a strong connection with the total commute.

Commute travel significantly changes the individual carbon footprint. (Wang and Zeng 2019) Results show that CO 2 emissions due to commuting in Beijing in recent years has presented an increasing trend. Commuters with access to a car, those having a higher income, and those located in the outer regions of the main urban areas produce more CO 2 emissions. From the analysis, it was evident that entrepreneurs who tend to travel more and this frequent commutation has reflected in their commute carbon footprint. 
2.4: Comparison of annual income with total carbon footprint. The annual income of the respondents greatly influences their annual carbon footprint. This is because as income increase we can sense variations in their consumption and expenditure pattern, because of which the carbon footprint will also vary. Table 3 underneath shows the differences in annual income and carbon footprint.

Table 3 categorizes the respondents based on their annual income and total carbon footprint

\begin{tabular}{|c|c|c|c|}
\hline $\begin{array}{l}\text { Annual Income } \\
\text { category }\end{array}$ & $\begin{array}{cc}\text { Number } & \text { of } \\
\text { Respondents } & \end{array}$ & $\begin{array}{l}\text { Total average } \\
\text { carbon footprint }\end{array}$ & $\begin{array}{c}\text { Percentage } \\
\text { carbon footprint }(\%)\end{array}$ \\
\hline Up to 2.5 lakhs & 82 & $2821.01 \mathrm{~kg}$ of $\mathrm{CO} 2 \mathrm{e}$ & 8.4 \\
\hline 2.5 lakhs- 5 lakhs & 19 & $8068.15 \mathrm{~kg}$ of $\mathrm{CO} 2 \mathrm{e}$ & 24.2 \\
\hline 5-10 lakhs & 19 & $11927.10 \mathrm{~kg}$ of $\mathrm{CO} 2 \mathrm{e}$ & 35.7 \\
\hline Above 10 lakhs & 5 & $10522.6 \mathrm{~kg}$ of CO2e. & 31.5 \\
\hline Total & 125 & $33338.86 \mathrm{~kg}$ & 100 \\
\hline
\end{tabular}

From the table 3 , it is understood that the respondents are diversely distributed across the given income limits. Majority of the respondents come under the up to 2.5 lakhs limit and add up to only 8.4 per cent of the carbon footprint from that category. Almost 24.2 per cent of the carbon footprint belongs to the respondents from 2.5 lakhs - 5 lakhs category. 35.7 per cent of the carbon footprint is contributed from the respondents of the 5-10 lakhs category. 31.5 per cent of the carbon footprint is given by the respondents from the above 10 lakhs category. Notably, 67 per cent of the high-income earners are responsible for huge amounts of emissions. It is also surprising to note that more than $10,000 \mathrm{~kg}$ of $\mathrm{CO} 2 \mathrm{e}$ is mainly emitted by only 24 respondents with high earning capacity. Thus we can conclude that the average carbon footprint increases along with the increase in their respective income level.

Annual income influences carbon footprint, the value of correlation is 0.36 which is comparatively less influential than the commute correlation. Hence, it is determined that annual income has impact on total carbon footprint.

Annual income is determining the total carbon footprint, but not as effective as the influence of commute. Yet, income is found to be impacting carbon footprint especially with the increase in high-income class.

\section{Suggestive Measures for managing Vehicular Emissions:}

Commute emissions can be reduced by promoting the usage of electric vehicles or by encouraging lots of vehicle poolers. When people travel from work to home and vice versa they tend to emit lots of carbon in the pursuit of driving vehicles which are mostly outdated. Defects in vehicle's model are quite important because it is a significant factor which taken proper care, can emit lesser amounts of pollutants. Increased usage of public transport and car-pooling can act as an effective measure to prevent the widespread usage of vehicles. Combining the everyday workload and the to-do list can avoid the frequent usage of vehicles. Cycling is also another method where we can avoid the pollution rate. Walking and reducing our dependence on petroleum products acts as a low carbon alternative. Reducing our consumption expenditure and procuring what we need is also a better option to reduce our family spend carbon footprint. Using energy-efficient products / Eco- friendly products can prolong the utility of the particular product. We must switch to green electricity and other forms of renewable sources.

Policymakers should formulate policies that promote the use of electric vehicles. Such electric vehicles can be sold at concessional rates or such consumers can be given some deduction from their tax burden or any forms of benefits which attract people to adopt this shift. Strict laws must be enforced to control the vehicle induced pollution. Government should promote low carbon-intensive products. It can lend financial support to the companies which do business in sustainable ways.

\section{Conclusion:}

Repeated acts like local commute, diet consumption, travel, energy needs and household spending pattern are the game-changers. Lack of awareness about the emissions from the above-mentioned variables are a vital cause for spurring of carbon emissions. Even if complete obliteration of emissions is not possible, then attainable steps can be adopted to reduce its severity towards the environment. This sort of an initiative must happen at all spheres right from individuals to giant societal structures. Carbon footprint is substantially influenced by the mode of travel and level of income and spending. Necessary modifications must be built to control travel emissions, diet 
based emissions, energy and consumption induced emissions and other threatening prospects which stimulate carbon emissions.

\section{References}

https://onlyplanet.in/question

M.I Irfany and S.Klasen, "Inequality in emissions: evidence from Indonesian household" Environmental Economics and Policy Studies, 18(4), 2016, pp.459-483.

https://doi.org/10.1007/s10018-015-0119-0

M. N. Seriño," The Rising Carbon Footprint of Philippine Households: An Estimation Using Consumption Expenditure and Input-Output Analysis", Annals of Tropical Research, 2016, pp. 1-16. https://doi.org/10.32945/atr3821.2016

H. Wang and W. Zeng, " Revealing urban carbon dioxide (CO 2 ) Emission characteristics and influencing mechanisms from the perspective of commuting”, Sustainability (Switzerland), 2019, 11(2).https://doi.org/10.3390/su11020385

S. Shukla, S Singal. and D. K. Sharma, "Emission of carbon dioxide by urban households." Ecology, Environment and Conservation, 19(4), 2013, pp. 1123-1125.

Q. Qiu, Y. Zhao, L. Chen and Y. Quan, "Utilization of Urban Form Information for Extracting Commuting Travel Carbon Emission on Urban Road Network", Institute of Electrical and Electronics Engineers (IEEE) 2012, pp. 895-895. https://doi.org/10.1109/itng.2012.88

M. Abdallah, A. M Tawfik, S. Monghasemi, C. M.Clevenger and B. A. Adame, " Developing commute optimization system to minimize negative environmental impacts and time of business commuters" International Journal of Sustainable Transportation, 14(2), 2019, pp. 101-119. https://doi.org/10.1080/15568318.2018.1531184

https://doi.org/10.1016/j.ecolecon.2012.04.027 